\title{
Speech \& Language Pathologists Interpretation of Pure Tone Audiometrical Test
}

Rana $\mathrm{KK}^{1 *}$, Ahmad $\mathrm{U}^{2}$ and Bhutta $\mathrm{AH}^{3}$

${ }^{1}$ Contribution Includes Conception \& Designing; Revised

and Accountable for all Aspects, Pakistan

${ }^{2}$ Auditory Verbal Institute of Audiology and Speech

Rawalpindi, Contribution Includes Research Designing,

Revised and Accountable for all Aspects, Pakistan

${ }^{3}$ Helping Hand Institute of Rehabilitation Sciences,

Pakistan

*Corresponding author: Kamran Khan Rana, Senior Speech Therapist/ Senior Lecturer, Contribution Includes Conception \& Designing, Revised and Accountable for all Aspects, Helping Hand Institute of Rehabilitation Sciences, Mansehra, KPK, Pakistan

Received: December 22, 2020; Accepted: February 22, 2021; Published: March 01, 2021

\begin{abstract}
Background: Facilitation of hearing impaired is important because a large amount of hearing impaired whose are still awaited for speech and language therapy. Persons With Disabilities (PWDS) statistics in Pakistan recently released the results of prevalence of Hearing impairment in Pakistan. The data indicates that deaf /mute population is $n=380548$ in number. This shows a large amount of Pakistani population facing the problem of speech and hearing. The current study was conducted to establish speech and language pathologists are being able to interpret the Pure Tone Audiometrical tests and to facilitate them with speech therapy.
\end{abstract}

Objective: To evaluate how much well interpretation speech therapist can do in clinical setup.

Methodology: The study was a quantitative survey based. The survey study was selected to analyze the knowledge of SLPs regarding the interpretation of pure tone audiometrical tests. Data was collected form 43 speech and language pathologist/therapists from Lahore, Faisalabad and Rawalpindi/Islamabad who were working with the hearing impairment. All the SLPs were qualified clinicians who were working in school and private clinic settings. The participants were MS degree in SLP and diploma in SLT holder was included in the study. But those whose experiences were less than year excluded from this study. A pre designed self-made questionnaire was designed which includes 20 items. Each question was valid to assess the knowledge regarding pure tone audiometrical test. Data was analyzed through SPSS. The result shows that speech and language pathologists were aware about the interpretation of audiometrical test and developing speech of hearing impaired persons.

Conclusion: The study showed that SLP's were having mild to moderate level interpretation skills which must be enhanced to upgrade the professional practice and better clinical practice in management of hearing issues.

Keywords: Speech Language Pathology; Audiometry; Hearing aid; Disability prevention

\section{Introduction}

The term "hearing impairment" is a generic term which includes both situation who are deaf and those who are hard of hearing and refers to individual with any type or degree of hearing loss that interferes with development $[1,2]$.

Deafness means a hearing impairment that is so severe that the student is impaired in processing linguistic information through hearing, with or without amplification [3]. The term hard of hearing refers to students with hearing impairment who have permanent or fluctuating hearing loss which is less severe than the hearing loss of students who are deaf and which generally permits the use of the auditory channel as the primary means of developing speech and language skills [4].

When describing hearing loss it is categorized into three basic types of hearing loss, the conductive, sensorineural and mixed hearing loss. The degree of hearing loss refers to the severity of the loss [5]. The Silverman (1960), Goodman (1965) and American Speech Language Hearing Association (ASHA), the degrees of hearing threshold is as under, Normal range (0dB to $25 \mathrm{~dB})$ Mild range $(26 \mathrm{~dB}$ to $40 \mathrm{~dB})$ Moderate range ( $41 \mathrm{~dB}$ to $70 \mathrm{~dB}$ ) Sever range ( $71 \mathrm{~dB}$ to $90 \mathrm{~dB}$ ) Profound range (91dB and above) [6].

People with hearing impairments require services of the speech and language pathologist [7]. Most individual with hearing impairment require the services of a speech and language pathologist that may be direct, collaborative and consultative or a combination of these [7]. For the indivuals who does not require direct remedial services, the speech and language pathologist may assist in designing and implementing support for the family member or class teacher [8]. This may include preferential seating, room amplification, listening centers and personal FM system $[9,10]$. The role of the speech and language pathologist with a deaf student who does not use an amplification system (hearing aid) and uses Sign Language with no speech for communication may be to serve the classroom teacher as a consultant for literacy issues [11].

An Audiologist is a professional who specializes in evaluating and treating people with hearing loss [12], Audiologists have extensive 
training and skills to evaluate the hearing of adults, infants and children of all ages $[13,14]$. Audiologists conduct a wide variety of tests to determine the exact nature of an individual's hearing problem. Audiologists present a variety of treatment options to patients with hearing impairment. Audiologists dispense and fit hearing aids, administer tests of balance to evaluate dizziness and provide hearing rehabilitation training and refer patients to physicians when the hearing problem needs medical or surgical evaluation and also refer to SLPs for their speech. The SLP is dependent on the Audiologist for an accurate assessment as only post assessment effective intervention can be provided [15]. The audiologist conducts the several type of assessment. I.e. audiometry, tympanometry, ASSR and BERA etc. for hearing threshold [16].

\section{Materials and Methods}

The study was a quantitative survey based. The survey study was selected to analyze the knowledge of speech and language pathologist's skills to interpretation of pure tone audiometrical test. The study utilized purposive sampling of 43 speech and language pathologists working in private and Government settings. The convenient sampling was used. It is ensuring that educational background and experience of participants should be at least MS degree in speech pathology or diploma in speech therapy, they should have experience of working with hearing impairment. The participants had experience of working in clinical and school settings, likewise the respondents had adequate experience of working with hearing impaired children. Those speech and language pathologists who do not have diploma or MS degree in speech and language pathology from recognized institute and have less than one year of experience with hearing impairment were not include. The purposive sampling was used as only speech and language pathologist were recruited from Lahore, Faisalabad and Rawalpindi/Islamabad only. A pre designed selfmade questionnaire was distributed personally and via e-mail to the participants in hospitals, clinics and schools. They were informed about the purpose of the study. A short information consent form was given to participants with a choice to with draw from the study or any part either to participate. The participants assured that information provided by them will be kept confidential. The questionnaire consist of 20 items include 4 different cases, that were reliable and valid to check the SLPs knowledge about the interpretation of pure tone audiometrical tests.

\section{Special test}

Speech audiometry is a subjective test: Measurement of speech listening skill, including speech awareness and speech recognition. Speech audiometry augment the findings of pure tone test and help to determine the actual loss of patient's hearing.

Tympanometry: Tympanometry is a test for the evaluation of the middle ear including eardrum middle-ear function. It helps to detecting fluid in the middle ear. Negative pressure in the middle ear, any disruption of the ossicular bones any perforation of the eardrum and otosclerosis. It also help to determine the loss due to middle ear disfunctioning. This test is conducted through the tympanometer and graphical representation plotted on tympanogram.

Electrophysiological tests: This test is used for the assessment of inner ear. This test is used when the outer hair cells are stimulated that are located in the cochlea. That cell is send information to the brain and also sends backward towards the middle ear, through the ossicles, tympanic membrane and the external auditory canal.

Acoustic reflex testing: Acoustic reflex testing consists of two tests, which are stapedius and tensor tympani. Stapedius process determining when stapedius muscle to tighten the stapes and the tensor tympani reflex measure when eardrum movement in response to intense sound.

Auditory Brainstem Response (ABR): Is the computerized test, which is used to test the collect information about the inner ear, the cochlea and the pathway, which leads to the brain for hearing. This test is used for just only those children who have multiple disorders and who can't respond to the standard hearing tests.

Otoacoustic Emissions (OAES): In this test the cochlea is stimulated by a sound. When the sound stimulates the cochlea the hair cells of the cochlea vibrate. This vibration produces a sound that create resonance into the middle ear. The sound can be measured with a small probe inserted into the ear canal. This test is used for newborns with hearing problem. This test is screaming program and also detects the problems of external auditory canal; check the middle ear pressure both side of the tympanic membrane, fluid in the middle ear and damage to the outer hair cells in the cochlea.

Pure Tone audiometry: The pure tone audiometry test is used for the children who are above the age 3 years. In this test a single tone is used as a stimulus. In this testing certain stimuli are presented to one or both ears of the client at varying intensity level so the hearing thresh hold can be measured.

Pure Tone Audiometry is a test, which is used to assess the hearing threshold on different frequencies. We can see how much and what kind of hearing loss the client shows on each frequencies, which are plotted on the audiogram.

Pure Tone Audiometry gives us information about type, severity of hearing loss and residual hearing of the patient. Pure Tone Audiometry (PTA) is used to check hearing sensitivity in patients of hearing and speech problems. Production of speech sounds depends upon hearing and speech and language pathologist also deal with speech and hearing that's why speech and language pathologist plays a very important role for the assessment of speech problems with hearing.

\section{Results}

According to statistical analysis there were $n=43$. The participant's responses were calculated in percentages. The questionnaire was formed with 20 items; the first 12 questions were in the form of cases. Each case consists of 3 questions. In cases, they identify the severity, problem in speech sounds and selection for therapy. The total numbers of respondents were 43 including $81.4 \%$ were female and $18.6 \%$ were male. This pie chart \# shows that $81.4 \%$ of the respondents are 20 to 30 years of age while $18.6 \%$ of the respondents are 31 to 40 years of age. $53.5 \%$ of the respondents were having M.S SLP/T degree while the rest of $46.5 \%$ of the respondents were PGD in SLT diploma. $7 \%$ of the respondents work in hospital, $9.3 \%$ in clinical while the rest of $83.7 \%$ of the respondents work in school setup. $79.1 \%$ of the respondents were Govt. employees while the rest of $20.9 \%$ of the 


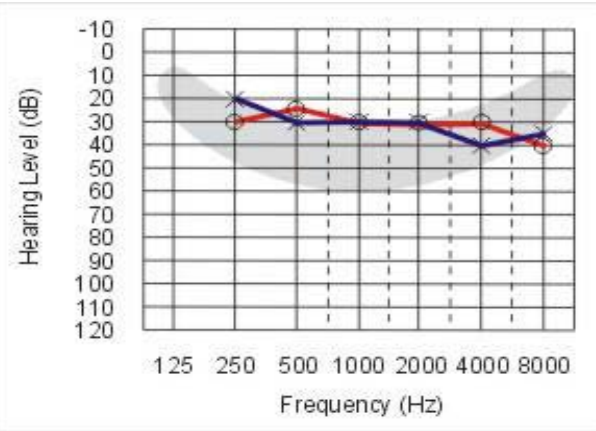

Figure 1: Case I Audiogram.

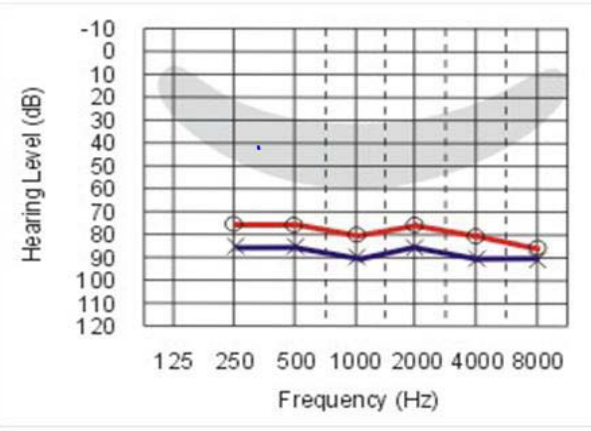

Figure 2: Case II Audiogram.

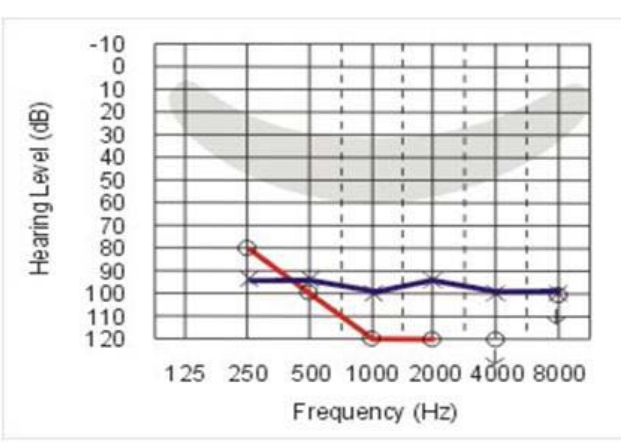

Figure 3: Case III Audiogram.

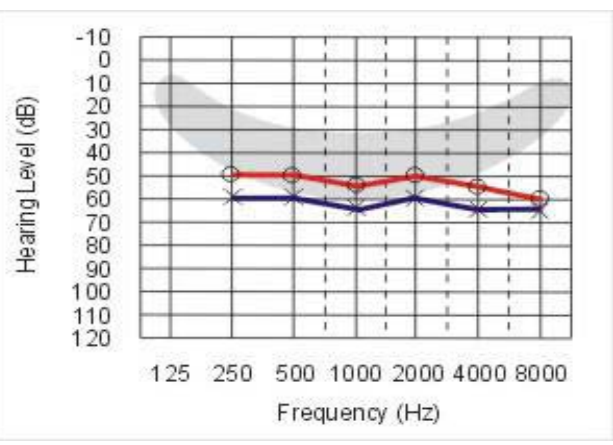

Figure 4: Case IV Audiogram.

respondents work in private setup. Further analysis states that $62.8 \%$ of the respondents had 1 to 2 years work experience, $27.9 \% 3$ to 4
Table 1: Case I interpretation by SLP's.

\begin{tabular}{|c|c|c|}
\hline (Case I) & Responses & n (\%) \\
\hline \multirow{2}{*}{$\begin{array}{l}\text { What type of hearing loss is evident } \\
\text { from the above provided Audiogram? }\end{array}$} & Mild & $33(76 \%)$ \\
\hline & Moderate & $10(23 \%)$ \\
\hline \multirow{5}{*}{$\begin{array}{l}\text { This audiogram results indicate the } \\
\text { patient is unable to hear? }\end{array}$} & $\begin{array}{l}\text { a whispered } \\
\text { communication in a quiet } \\
\text { atmosphere at close }\end{array}$ & $9(21 \%)$ \\
\hline & $\begin{array}{l}\text { a whispered } \\
\text { communication in a noisy } \\
\text { atmosphere at close }\end{array}$ & $20(46 \%)$ \\
\hline & high frequencies & $6(14 \%)$ \\
\hline & low frequencies & $6(14 \%)$ \\
\hline & don't know & $2(4.6 \%)$ \\
\hline \multirow{3}{*}{$\begin{array}{l}\text { Is this patient a true candidate for } \\
\text { speech therapy? }\end{array}$} & Yes & $37(86 \%)$ \\
\hline & No & $3(14 \%)$ \\
\hline & Don't know & $3(14 \%)$ \\
\hline
\end{tabular}

Table 2: Case II Interpretation by SLP.

\begin{tabular}{|c|c|c|}
\hline (Case II) & Responses & n (\%) \\
\hline \multirow{3}{*}{$\begin{array}{l}\text { What type of hearing loss is evident from the } \\
\text { above provided Audiogram? }\end{array}$} & Moderate & $2(4.6 \%)$ \\
\hline & Severe & $37(86 \%)$ \\
\hline & Profound & $4(9 \%)$ \\
\hline \multirow{4}{*}{$\begin{array}{l}\text { This audiogram results indicate the patient is } \\
\text { unable to hear? }\end{array}$} & $\begin{array}{l}\text { a whispered } \\
\text { conversation }\end{array}$ & $10(2 \%)$ \\
\hline & $\begin{array}{l}\text { Normal conversation } \\
\text { (speech) }\end{array}$ & $23(53 \%)$ \\
\hline & high frequencies & $2(4.6 \%)$ \\
\hline & don't know & $8(18.6 \%)$ \\
\hline \multirow{3}{*}{$\begin{array}{l}\text { Is this patient a true candidate for speech } \\
\text { therapy? }\end{array}$} & Yes & $39(90.6 \%)$ \\
\hline & No & $2(4.6 \%)$ \\
\hline & Don't know & $2(4.6 \%)$ \\
\hline
\end{tabular}

Table 3: Case III interpretation by SLP.

\begin{tabular}{|c|c|c|}
\hline (Case III) & Responses & n (\%) \\
\hline \multirow{3}{*}{$\begin{array}{l}\text { What type of hearing loss is evident from the } \\
\text { above provided Audiogram? }\end{array}$} & Moderate & $4(9.3 \%)$ \\
\hline & Severe & $21(48.8 \%)$ \\
\hline & Profound & $18(41.8 \%)$ \\
\hline \multirow{5}{*}{$\begin{array}{l}\text { This audiogram results indicate the patient is } \\
\text { unable to hear? }\end{array}$} & $\begin{array}{l}\text { a whispered } \\
\text { conversation }\end{array}$ & $6(13.9 \%)$ \\
\hline & All speech sounds & $16(37.2 \%)$ \\
\hline & Whisper sounds & $7(16.2 \%)$ \\
\hline & high frequencies & $6(13.9 \%)$ \\
\hline & don't know & $8(18.6 \%)$ \\
\hline \multirow{3}{*}{$\begin{array}{l}\text { Is this patient a true candidate for speech } \\
\text { therapy? }\end{array}$} & Yes & $33(76.7 \%)$ \\
\hline & No & $6(13.9 \%)$ \\
\hline & Don't know & $4(9.3 \%)$ \\
\hline
\end{tabular}

years while the rest of $9.3 \%$ of the respondents 5 to 6 years of work experience. In this question "What of hearing loss is evident from the above provided Audiogram?" The table No. 1 shows that $76.7 \%$ of the respondents responded "mild" which is correct while rest of $23.3 \%$ respondent respond "moderate" which is incorrect answer.

\section{Discussion}

Primary objective of the study was to evaluate how appropriate 
Table 4: Case IV Interpretation by SLP.

\begin{tabular}{|c|c|c|}
\hline (Case IV) & Responses & n (\%) \\
\hline \multirow{3}{*}{$\begin{array}{l}\text { What type of hearing loss is evident } \\
\text { from the above provided Audiogram? }\end{array}$} & Moderate & $39(90.6 \%)$ \\
\hline & Profound & $2(4.6 \%)$ \\
\hline & Don't know & $2(4.6 \%)$ \\
\hline \multirow{4}{*}{$\begin{array}{l}\text { This audiogram results indicate the } \\
\text { patient is unable to hear? }\end{array}$} & $\begin{array}{l}\text { a whispered } \\
\text { communication in a quiet } \\
\text { atmosphere at close }\end{array}$ & $2(4.6 \%)$ \\
\hline & $\begin{array}{l}\text { a whispered } \\
\text { communication in a noisy } \\
\text { atmosphere at close }\end{array}$ & $23(53.4 \%)$ \\
\hline & $\begin{array}{l}\text { Normal communication } \\
\text { in a quiet atmosphere at } \\
\text { close }\end{array}$ & $14(32.5 \%)$ \\
\hline & don't know & $4(9.3 \%)$ \\
\hline \multirow{3}{*}{$\begin{array}{l}\text { Is this patient a true candidate for } \\
\text { speech therapy? }\end{array}$} & Yes & $39(90.6 \%)$ \\
\hline & No & $2(4.6 \%)$ \\
\hline & Don't know & $2(4.6 \%)$ \\
\hline
\end{tabular}

Table 5:

\begin{tabular}{|c|c|c|}
\hline Question & Correct & False \\
\hline $\begin{array}{l}\text { A patient reported with mixed hearing loss faces } \\
\text { difficulty in? }\end{array}$ & $10(23.2 \%)$ & $33(76.7 \%)$ \\
\hline $\begin{array}{l}\text { Conductive hearing loss is a problem in which part of } \\
\text { the ear? }\end{array}$ & $27(62.7 \%)$ & $16(37.3 \%)$ \\
\hline $\begin{array}{l}\text { If a patient is reported with sensoryneural hearing loss, } \\
\text { the problem is in? }\end{array}$ & $16(37.3 \%)$ & $27(62.7 \%)$ \\
\hline How to calculate Pure Tone Average sensitivity level? & $22(51.2 \%)$ & $21(48.8 \%)$ \\
\hline What is on ' $y$ ' axis of the audiogram? & $28(65.1 \%)$ & $15(34.9 \%)$ \\
\hline $\begin{array}{l}\text { The Red 'O' symbol indicates which of the following on } \\
\text { the audiogram? }\end{array}$ & $1(2.3 \%)$ & 42(97.7) \\
\hline $\begin{array}{l}\text { What frequencies are tested in PTA air conduction } \\
\text { audiometry? }\end{array}$ & $21(48.9 \%)$ & $22(51.1)$ \\
\hline $\begin{array}{l}\text { What frequencies are tested in PTA bone conduction } \\
\text { audiometry? }\end{array}$ & 16(37.2) & $27(62.7 \%)$ \\
\hline
\end{tabular}

the interpretation of scenario based audiogram by speech therapist, the first 12 question were in the form of four cases. The secondary objective was to evaluate how appropriate the interpretation of Audiogram was by the SLP's.

The range of mild degree was $26 \mathrm{~dB}$ to $40 \mathrm{~dB}$, that client who had diagnosed with mild degree "Difficult to identify soft sound such as whispering, has difficulty hearing faint speech, needs favorable setting, hearing aid, auditory training, lip reading instructions, speech conversation and speech correction" [17].

The first question of case 1 defined the severity of the hearing impairment. For the first question $76.7 \%$ of the respondents responded correctly answer while $23.3 \%$ of the respondents responded incorrectly answer. The $2^{\text {nd }}$ question of the same case looked at deficiency of speech sound, this question had $20.9 \%$ correctly answers while $79.1 \%$ were unable to respond correctly. The $3^{\text {rd }}$ question of this case questioned the need for speech therapy, $86 \%$ of the respondents responded correctly while $14 \%$ of the respondents failed to provide a correct response. The range of moderate degree was $41 \mathrm{~dB}$ to $70 \mathrm{~dB}$, that client who had diagnosed with moderate degree "cannot hear normal conversation in a quiet atmosphere at close, needs favorable setting, auditory training, lip reading instructions, conversation must be loud to be understood and there is a great difficulty in a group and class room discussion, Hearing aids and speech \& language therapy is necessary [12]".
In the second case, $3^{\text {rd }}$ questions in which for the $1^{\text {st }}$ question $86 \%$ of the respondents responded correctly answer. The second question of the same case consisted of addressing deficiency of speech sounds, the $53.5 \%$ of the respondents responded correctly. The $3^{\text {rd }}$ question of this case was looked at the need for speech therapy, $90.7 \%$ of the respondents responded correctly answer while $9.3 \%$ of the respondents failed to provide correct responses.

The range of sever degree was $71 \mathrm{~dB}$ to $90 \mathrm{~dB}$, that client who had diagnosed with sever degree "Can only hear very loud noises and sounds such as shouting or vacuum cleaner noise, lawn mower, at close distances 60-90 dB loss, needs special education for deaf children with emphasis on speech, auditory training, Hearing aids and speech \& language therapy is necessary, may enter into regular classes at a later time".

The third case was also distributed in the same manner and 1st $41.9 \%$ of the respondents responded correctly. The second question of the same case the deficiency targeted of speech sounds, the $37.2 \%$ of the respondents responded correctly. The third question looked at for speech therapy, $76.7 \%$ of the respondents responded correctly while $23.3 \%$ of the respondents failed to provide correct responses.

The range of profound degree was above $90 \mathrm{~dB}$, that client who had diagnosed with profound degree "Difficult to perceive any sound, cannot hear speech, may lonely hear very loud noises such as a chain saw at close range or the vibrating component of a loud sound, high power hearing aids and speech \& language therapy is necessary".

The first question of case 4 defined the severity of the hearing impairment. For the first question, $90.7 \%$ of the respondents responded correctly. The second question of the same case deficiency of speech sounds, the $4.7 \%$ of the respondents responded correctly. The third question looked at for speech therapy, $90.7 \%$ of the respondents responded correctly while $9.3 \%$ of the respondents failed to provide correct responses.

This study also looked at individual questions.

In question $13,23.3 \%$ of the respondents responded correctly while $76.7 \%$ of the respondents failed to provide correct responses.

When bone conduction is in better range rather than the air conduction audiometry and the bone conduction, results in normal range its mean the conductive hearing loss. In this loss, there are some disruption in external canal in the form of wax, foreign object, eardrum perforation or other problem in the outer and the middle ear like otitus media.

In question $14,62.8 \%$ of the respondents responded correctly while $37.2 \%$ of the respondents failed to provide correct responses.

Sensoryneural problem in hearing occurs when there are some disfunctioning with the cochlea or the auditory pathway.

In question $15,37.2 \%$ of the respondents responded correctly while $62.8 \%$ of the respondents failed to provide correct responses.

The studies shows that speech frequencies are $500+1000+2000$ calculate and dived into the 3 shown that the $\mathrm{dB}$ average of these three frequencies serves quiet well in the predicting the threshold for understanding speech. 
In question $16,51.2 \%$ of the respondents responded correctly while $48.8 \%$ failed to provide correct responses. In question 17 , $65.1 \%$ of the respondents responded correctly while $34.9 \%$ failed in their responses. In question $18,76.7 \%$ of the respondents responded correctly while $23.3 \%$ failed in their responses. In question 19 , $48.8 \%$ of the respondents responded correctly while $51.2 \%$ of the respondents failed in their responses. In question $20,37.2 \%$ of the respondents responded correctly while $62.8 \%$ of the respondents failed in their responses.

No researches or study, were available to the researcher to compare the result of this study.

\section{Conclusion}

The study concludes that speech and language pathologist have mild to moderate knowledge about the pure tone audiometrical test. There were no marked difference respondents with MS degree and PGD diploma holder in speech and language pathology. Both groups viewed in mild to moderate interpretational skills regarding pure tone audiometrical tests. The study investigated about interpretation of audiogram, define its severity and selection for speech therapy. The study has also identified that there is a great number of women choosing to become SLPs total $81 \%$ of the surveyed population comprised of females. In addition, the vast majority of these participants were under 31 years of age. There are only 8 participants 30 to 40 years of age.

\section{References}

1. Domingo J, Bradley E. Training Special Education Teachers through Computer Simulations: Promoting Understanding of the Experiences of Students with Disabilities. Games and Simulations in Teacher Education: Springer. 2020: 75-89.

2. Schädler MR, Hülsmeier D, Warzybok A, Kollmeier B. Individual Aided Speech-Recognition Performance and Predictions of Benefit for Listeners with Impaired Hearing Employing FADE. Trends in Hearing. 2020; 24 2331216520938929

3. Warzybok A, Zhilinskaya E, Goykhburg M, Tavartkiladze G, Kollmeier B Boboshko M. Clinical validation of the Russian Matrix test-effect of hearing loss, age, and noise level. Int J Audiol. 2020: 1-11.

4. Paterson J, Purdy SC, Tautolo E-S, Iusitini L, Schluter PJ, Sisk R. The
Association between Hearing Impairment and Problem Behaviors in 11-YearOld Pacific Children Living in New Zealand. Ear Hear. 2020; 41: 539-548.

5. Chandrasekhar SS, Tsai Do BS, Schwartz SR, Bontempo LJ, Faucett EA, Finestone SA, et al. Clinical practice guideline: sudden hearing loss (update) Otolaryngology-Head and Neck Surgery. 2019; 161: S1-S45

6. Bilger RC, Nuetzel J, Rabinowitz WM, Rzeczkowski C. Standardization of a test of speech perception in noise. J Speech Lang Hear Res. 1984; 27: 32-48.

7. Association AS-L-H. Scope of practice in speech-language pathology. 2016.

8. Bopp KD, Brown KE, Mirenda P. Speech-language pathologists' roles in the delivery of positive behavior support for individuals with developmental disabilities. Am J Speech Lang Pathol. 2004.

9. Picou EM, Lewis D, Angley G, Tharpe AM. Rerouting hearing aid systems for overcoming simulated unilateral hearing in dynamic listening situations. Ear Hear. 2020; 41: 790-803.

10. Updike CD. Comparison of FM auditory trainers, CROS aids, and personal amplification in unilaterally hearing impaired children. Journal-American Academy of Audiology. 1994; 5: 204.

11. Trussell JW, Easterbrooks SR. Morphological knowledge and students who are deaf or hard-of-hearing: A review of the literature. Communication Disorders Quarterly. 2017; 38: 67-77.

12. Yong M, Willink A, McMahon C, McPherson B, Nieman CL, Reed NS, et al. Access to adults' hearing aids: policies and technologies used in eight countries. Bull World Health Organ. 2019; 97: 699-710.

13. Ching TY, Hou S, Seeto M, Harkus S, Ward M, Marnane V, et al. The Parents' evaluation of Listening and Understanding Measure (PLUM): Development and normative data on Aboriginal and Torres Strait Islander children below 6 years of age. Deafness \& Education International. 2020; 22: 288-304.

14. Meibos A, Muñoz K, Schultz J, Price T, Whicker JJ, Caballero A, et al. Counselling users of hearing technology: A comprehensive literature review. Int J Audiol. 2017; 56: 903-908.

15. Beukes EW, Allen PM, Baguley DM, Manchaiah V, Andersson G. Long-term efficacy of audiologist-guided Internet-based cognitive behavior therapy for tinnitus. American journal of audiology. 2018; 27: 431-447.

16. Atas A, Aksoy S, am Zehnhoff-Dinnesen A, Bamiou D-E, Bartel-Friedrich S, Benton C, et al. Diagnosis and Differential Diagnosis of Disorders of Hearing Development. Phoniatrics I: Springer. 2020: 857-961.

17. Sinha S, Irani UD, Manchaiah V, Bhamla MS. LoCHAid: An ultra-low-cost hearing aid for age-related hearing loss. PLoS One. 2020; 15: e0238922. 